\title{
Manual small incision cataract surgery (MSICS) with posterior chamber intraocular lens versus extracapsular cataract extraction (ECCE) with posterior chamber intraocular lens for age-related cataract (Review)
}

Ang M, Evans JR, Mehta JS

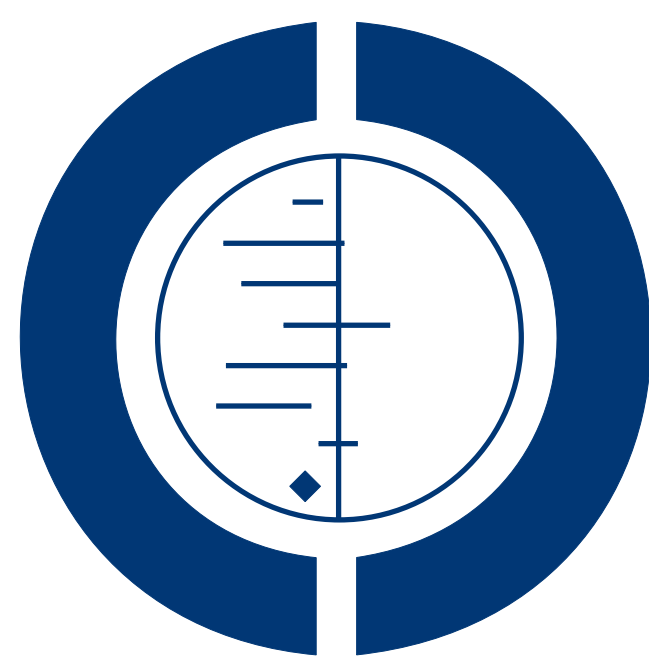

THE COCHRANE COLLABORATION ${ }^{\circledR}$

This is a reprint of a Cochrane review, prepared and maintained by The Cochrane Collaboration and published in The Cochrane Library 2012, Issue 4

http://www.thecochranelibrary.com

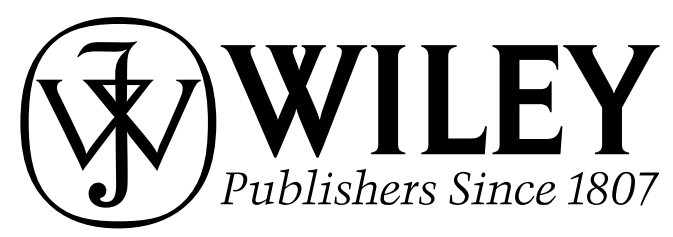

Manual small incision cataract surgery (MSICS) with posterior chamber intraocular lens versus extracapsular cataract extraction (ECCE) with posterior chamber intraocular lens for age-related cataract (Review)

Copyright $\odot 2012$ The Cochrane Collaboration. Published by John Wiley \& Sons, Ltd. 
TABLE OF CONTENTS

HEADER . . . . . . . . . . . . . . . . . . . . . . . . . . . . . . . . . . . . . . . 1

ABSTRACT . . . . . . . . . . . . . . . . . . . . . . . . . . . . . . . . . . . . . . . . . . . . . . . . 1

PLAIN LANGUAGE SUMMARY . . . . . . . . . . . . . . . . . . . . . . . . . . . . . . . . . . . . .

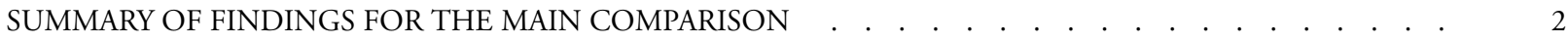

BACKGROUND . . . . . . . . . . . . . . . . . . . . . . . . . . . . . . . . . . . . . . 4

Figure 1. . . . . . . . . . . . . . . . . . . . . . . . . . . . . . . . . . . . . . .

OBJECTIVES . . . . . . . . . . . . . . . . . . . . . . . . . . . . . . . . . . . . . .

METHODS . . . . . . . . . . . . . . . . . . . . . . . . . . . . . . . . . . . . . . 7

RESULTS . . . . . . . . . . . . . . . . . . . . . . . . . . . . . . . . . . . . . . . 10

Figure 2. . . . . . . . . . . . . . . . . . . . . . . . . . . . . . . . . . . . . . 11

Figure 3. . . . . . . . . . . . . . . . . . . . . . . . . . . . . . . . . . . . . . 12

Figure $4 . \quad$. . . . . . . . . . . . . . . . . . . . . . . . . . . . . . . . . . . . . 13

DISCUSSION . . . . . . . . . . . . . . . . . . . . . . . . . . . . . . . . . . . . . 15

AUTHORS' CONCLUSIONS . . . . . . . . . . . . . . . . . . . . . . . . . . . . . . . . . . . .

ACKNOWLEDGEMENTS . . . . . . . . . . . . . . . . . . . . . . . . . . . . . . . . . 16

REFERENCES . . . . . . . . . . . . . . . . . . . . . . . . . . . . . . . . . . . . . . 16

CHARACTERISTICS OF STUDIES . . . . . . . . . . . . . . . . . . . . . . . . . . . . . . . . . . . 18

DATA AND ANALYSES . . . . . . . . . . . . . . . . . . . . . . . . . . . . . . . . . . . . . . . . . .

ADDITIONAL TABLES . . . . . . . . . . . . . . . . . . . . . . . . . . . . . . . . . . . . . . .

APPENDICES . . . . . . . . . . . . . . . . . . . . . . . . . . . . . . . . . . . . . . . . .

HISTORY . . . . . . . . . . . . . . . . . . . . . . . . . . . . . . . . . . . . . . . . .

CONTRIBUTIONS OF AUTHORS . . . . . . . . . . . . . . . . . . . . . . . . . . . . . . . . . . . . . . . . . .

DECLARATIONS OF INTEREST . . . . . . . . . . . . . . . . . . . . . . . . . . . . . . . . . . . . . . 27

SOURCES OF SUPPORT . . . . . . . . . . . . . . . . . . . . . . . . . . . . . . . . . . . . . . . . . . . . . . . .

NOTES . . . . . . . . . . . . . . . . . . . . . . . . . . . . . . . . . . . . . . . . . 27

INDEX TERMS . . . . . . . . . . . . . . . . . . . . . . . . . . . . . . . . . . . . . . . . . . . . . .

Manual small incision cataract surgery (MSICS) with posterior chamber intraocular lens versus extracapsular cataract extraction 
[Intervention Review]

\title{
Manual small incision cataract surgery (MSICS) with posterior chamber intraocular lens versus extracapsular cataract extraction (ECCE) with posterior chamber intraocular lens for age-related cataract
}

\author{
Marcus Ang ${ }^{1}$, Jennifer R Evans ${ }^{2}$, Jod S Mehta ${ }^{3}$ \\ ${ }^{1}$ Singapore National Eye Centre, Singapore, Singapore. ${ }^{2}$ Cochrane Eyes and Vision Group, ICEH, London School of Hygiene \& \\ Tropical Medicine, London, UK. ${ }^{3}$ Singapore Eye Research Institute, Singapore, Singapore \\ Contact address: Marcus Ang, Singapore National Eye Centre, 11 Third Hospital Avenue, Singapore, 168751, Singapore. \\ marcusahn@yahoo.com.sg.
}

Editorial group: Cochrane Eyes and Vision Group.

Publication status and date: New, published in Issue 4, 2012.

Review content assessed as up-to-date: 14 February 2012.

Citation: Ang M, Evans JR, Mehta JS. Manual small incision cataract surgery (MSICS) with posterior chamber intraocular lens versus extracapsular cataract extraction (ECCE) with posterior chamber intraocular lens for age-related cataract. Cochrane Database of Systematic Reviews 2012, Issue 4. Art. No.: CD008811. DOI: 10.1002/14651858.CD008811.pub2.

Copyright (C) 2012 The Cochrane Collaboration. Published by John Wiley \& Sons, Ltd.

\begin{abstract}
A B S T R A C T
Background

Age-related cataract is the opacification of the lens, which occurs as a result of denaturation of lens proteins. Age-related cataract remains the leading cause of blindness globally, except in the most developed countries. A key question is what is the best way of removing the lens, especially in lower income settings.

Objectives

To compare two different techniques of lens removal in cataract surgery: manual small incision surgery (MSICS) and extracapsular cataract extraction (ECCE).

Search methods

We searched CENTRAL (which contains the Cochrane Eyes and Vision Group Trials Register) (The Cochrane Library 2012, Issue 1), MEDLINE (January 1950 to February 2012), EMBASE (January 1980 to February 2012), Latin American and Caribbean Literature on Health Sciences (LILACS) (January 1982 to February 2012), Web of Science Conference Proceedings Citation Index- Science (CPCI-S), the metaRegister of Controlled Trials ( $m$ RCT) (www.controlled-trials.com), ClinicalTrials.gov (www.clinicaltrials.gov) and the WHO International Clinical Trials Registry Platform (ICTRP) (www.who.int/ictrp/search/en). There were no date or language restrictions in the electronic searches for trials. The electronic databases were last searched on 14 February 2012.
\end{abstract}

\section{Selection criteria}

We included randomised controlled trials (RCTs) only. Participants in the trials were people with age-related cataract. We included trials where MSICS with a posterior chamber intraocular lens (IOL) implant was compared to ECCE with a posterior chamber IOL implant.

Manual small incision cataract surgery (MSICS) with posterior chamber intraocular lens versus extracapsular cataract extraction

(ECCE) with posterior chamber intraocular lens for age-related cataract (Review)

Copyright $\odot 2012$ The Cochrane Collaboration. Published by John Wiley \& Sons, Ltd. 


\section{Data collection and analysis}

Data were collected independently by two authors. We aimed to collect data on presenting visual acuity $6 / 12$ or better and best-corrected visual acuity of less than $6 / 60$ at three months and one year after surgery. Other outcomes included intraoperative complications, longterm complications (one year or more after surgery), quality of life, and cost-effectiveness. There were not enough data available from the included trials to perform a meta-analysis.

\section{Main results}

Three trials randomly allocating people with age-related cataract to MSICS or ECCE were included in this review ( $\mathrm{n}=953$ participants). Two trials were conducted in India and one in Nepal. Trial methods, such as random allocation and allocation concealment, were not clearly described; in only one trial was an effort made to mask outcome assessors. The three studies reported follow-up six to eight weeks after surgery. In two studies, more participants in the MSICS groups achieved unaided visual acuity of 6/12 or 6/18 or better compared to the ECCE group, but overall not more than $50 \%$ of people achieved good functional vision in the two studies. $10 / 806$ $(1.2 \%)$ of people enrolled in two trials had a poor outcome after surgery (best-corrected vision less than 6/60) with no evidence of difference in risk between the two techniques (risk ratio (RR) 1.58, 95\% confidence interval (CI) 0.45 to 5.55). Surgically induced astigmatism was more common with the ECCE procedure than MSICS in the two trials that reported this outcome. In one study there were more intra- and postoperative complications in the MSICS group. One study reported that the costs of the two procedures were similar.

\section{Authors' conclusions}

There are no other studies from other countries other than India and Nepal and there are insufficient data on cost-effectiveness of each procedure. Better evidence is needed before any change may be implemented. Future studies need to have longer-term follow-up and be conducted to minimize biases revealed in this review with a larger sample size to allow examination of adverse events.

\section{PLAIN LANGUAGE SUMMARY}

\section{Comparison of two different methods of lens removal in cataract surgery, particularly relevant to lower income settings}

As people get older, the lens in the eye can become cloudy - this is known as a cataract. Age-related cataract is the most common cause of blindness in the world. Visual impairment due to cataract can be cured by a surgical operation removing the cloudy lens and replacing it with a plastic lens which is known as an intraocular lens or IOL. A key question is: what is the best way of removing the lens, especially in lower income settings? This review considers two ways of removing the lens: manual small incision surgery (MSICS) whereby the lens is fragmented and extracted through a small incision and extracapsular cataract extraction (ECCE) which is the standard technique whereby the lens is removed through a larger incision. The review includes three randomised controlled trials that have compared these two methods. 953 people with age-related cataract in India and Nepal were randomly allocated to MSICS and ECCE. The trial reports did not clearly describe some of the methods and in only one trial were people measuring outcomes masked to treatment group. Only two of the studies reported relevant data on visual acuity. People whose lens was removed with MSICS were more likely to achieve good functional vision, however, overall not more than $50 \%$ of people achieved good functional vision in the two studies. $1.2 \%$ of people enrolled in two trials had a poor outcome after surgery with best-corrected vision less than $6 / 60$. There was no evidence of any difference between the two groups with respect to this outcome. Surgically induced astigmatism was more common with the ECCE procedure than MSICS in the two trials that reported this outcome. In one study there were more intra- and postoperative complications in the MSICS group. One study reported that the costs of the two procedures were similar. There are no other studies from other countries other than India and Nepal and there are insufficient data on cost-effectiveness of each procedure. Better evidence is needed before any change may be implemented. Future studies need to have longer-term follow-up (six months) and conducted to minimize biases revealed in this review with a larger sample size to allow examination of adverse events. 
SUMMARY OF FINDINGS FOR THE MAIN COMPARISON [Explanation]

\section{MSICS compared with ECCE for age-related cataract}

Patient or population: people with age-related cataract

Settings: hospital

Intervention: MSICS

Comparison: ECCE

\begin{tabular}{|c|c|c|c|}
\hline Outcomes & $\begin{array}{l}\text { No of Participants } \\
\text { (studies) }\end{array}$ & $\begin{array}{l}\text { Quality of the evidence } \\
\text { (GRADE) }\end{array}$ & Comments \\
\hline $\begin{array}{l}\text { Good functional vision: present- } \\
\text { ing visual acuity of } 6 / 12 \text { or better } \\
\text { at } 6-8 \text { weeks }\end{array}$ & $\begin{array}{l}806 \\
(2)\end{array}$ & $\begin{array}{l}\oplus \oplus \bigcirc \bigcirc \\
\text { low }^{1,2}\end{array}$ & $\begin{array}{l}\text { More people in MSCIS group } \\
\text { achieved good functional vision. } \\
\text { Risk ratio (RR) (in favour of } \\
\text { MSICS) of } 1.29 \text { ( } 95 \% \text { confi- } \\
\text { dence intervals (CI) } 1.08 \text { to } 1.53 \text { ) } \\
\text { (Gogate 2003) and } 2.43 \text { (1.10 to } \\
\text { 5.34) (Gurung 2009). }\end{array}$ \\
\hline
\end{tabular}

Poor visual outcome after 806 surgery: best-corrected visual (2) acuity of $<6 / 60$ at $6-8$ weeks $\oplus \oplus \bigcirc \bigcirc$

low 1,3
Six people in MSICS group and four people in ECCE group had poor visual outcome (RR 1.58, $95 \% \mathrm{Cl} 0.45$ to 5.55 ) (Gogate 2003). No participant had poor outcome in Gurung 2009 (100 participants)

Intraoperative and immediate 953 post-operative complications

\section{$\oplus \bigcirc \bigcirc \bigcirc$}

very low ${ }^{4}$
There were no reported complications during surgery in the George 2005 and Gurung 2009 studies. In the PUNE study (Gogate 2003) , 21 of the patients in the MSICS group were converted to ECCE either due to density of cataract or because of small pupil. 29/358 $(8.1 \%)$ of the MSICS group and $17 / 383$ (4.4\%) of the ECCE group and had intraoperative complications (RR $1.83,95 \% \mathrm{Cl} 1.02$ to 3. 26). $18 / 358$ (6 with vitreous loss) in the MSICS group had posterior capsule tears compared to 10/ 383 (6 with vitreous loss) in the ECCE group (RR 1.93, 95\% $\mathrm{Cl} 0$. 90 to 4.12). Two patients in the MSICS group had iridodialysis

Long-term complications (one year or more after surgery)

No data: no trial reported long term follow-up. 


\begin{tabular}{lll}
\hline $\begin{array}{l}741 \\
\text { Cost-effectiveness }\end{array}$ & $\begin{array}{l}\text { } 1 \text { In the PUNE study (Gogate 2003) } \\
\text { very low }\end{array}$ & $\begin{array}{l}\text {, there was no significant differ- } \\
\text { ence in surgical time or cost be- } \\
\text { tween the two procedures, even } \\
\text { accounting for surgeon variation. }\end{array}$ \\
& $\begin{array}{l}\text { The average cost of ECCE was } \\
\text { USD 15.82, MSICS USD 15.68 } \\
\text { of which USD 11.34 was a fixed } \\
\text { facility cost common to both }\end{array}$ \\
\end{tabular}

GRADE Working Group grades of evidence

High quality: Further research is very unlikely to change our confidence in the estimate of effect.

Moderate quality: Further research is likely to have an important impact on our confidence in the estimate of effect and may change the estimate.

Low quality: Further research is very likely to have an important impact on our confidence in the estimate of effect and is likely to change the estimate.

Very low quality: We are very uncertain about the estimate.

1. Risk of bias: generation of allocation schedule, allocation concealment and masking of participants, personnel and outcome assessors not clearly described.

2. Inconsistency in trial results.

3. Imprecision: wide confidence intervals.

4. Lack of data.

\section{B A C K G R O U N D}

\section{Description of the condition}

Age-related cataract is the opacification of the lens, which occurs as a result of denaturation of lens proteins and this is not thought to be reversible. These changes are often bilateral although they can be asymmetric. Symptoms from cataracts include glare, blurred vision, progressive decrease in visual function and blindness.

\section{Description of the intervention}

Extracapsular cataract extraction (ECCE) was introduced with the development of microsurgical instrumentation in the early 1980 s. The lens content is removed through a large $12 \mathrm{~mm}$ incision leaving the posterior lens capsule intact. A posterior chamber intraocular lens (IOL) can then be placed in the capsular bag (Apple 1989; Duane 1986). If no IOL is implanted, aphakic glasses or contact lenses must be used. Extracapsular surgery has become the preferred method of extraction in economically advantaged countries and most surgeons in developing countries have been trained in this technique.

Further technological development has led to a majority of surgeons in developed countries adopting sutureless ECCE surgery (Norregaard 1999). This surgery uses either ultrasonic fragmentation (phacoemulsification) of the lens nucleus (Mehta 1999), or a manual fragmentation technique (Blumenthal 1992; Hennig 1999). Both suture and sutureless ECCE leave in place the posterior capsule of the lens. This keeps the anatomical barrier between the posterior and anterior segments of the eye and may reduce the risk of posterior segment complications. The disadvantage of all the extracapsular techniques is that the posterior lens capsule can become cloudy (Apple 1992) with the need for a primary or secondary capsulotomy by surgery or using a YAG laser. This increases the costs of surgery and incurs the risk of secondary complications (Javitt 1992).

Manual small incision cataract surgery (MSICS) was first described 
by Blumenthal (Blumenthal 1992). In Asia and Africa there has been a renewal of interest in this technique (Ruit 2000) as an alternative to phacoemulsification because it is considerably less costly but has similar benefits of rapid visual recovery and reduced astigmatism (Yorston 2005). It involves a $6 \mathrm{~mm}$ to $6.5 \mathrm{~mm}$ scleral incision, just large enough to allow insertion of a $6 \mathrm{~mm}$ IOL. There are various different techniques described for performing the capsulotomy in MSICS, for example, the can-opener (Gogate
2005), the continuous curvilinear capsulorhexis (Gogate 2003) and the endocapsular technique where the incision is from pupil margin to pupil margin. The cataract is delivered into the anterior chamber, hydroextracted and aspirated. The posterior capsule of the lens is left intact. This technique is technically more difficult than a standard manual ECCE.

Figure 1 is a flow diagram summarising the different types of cataract surgery. 
Figure I. Types of cataract surgery

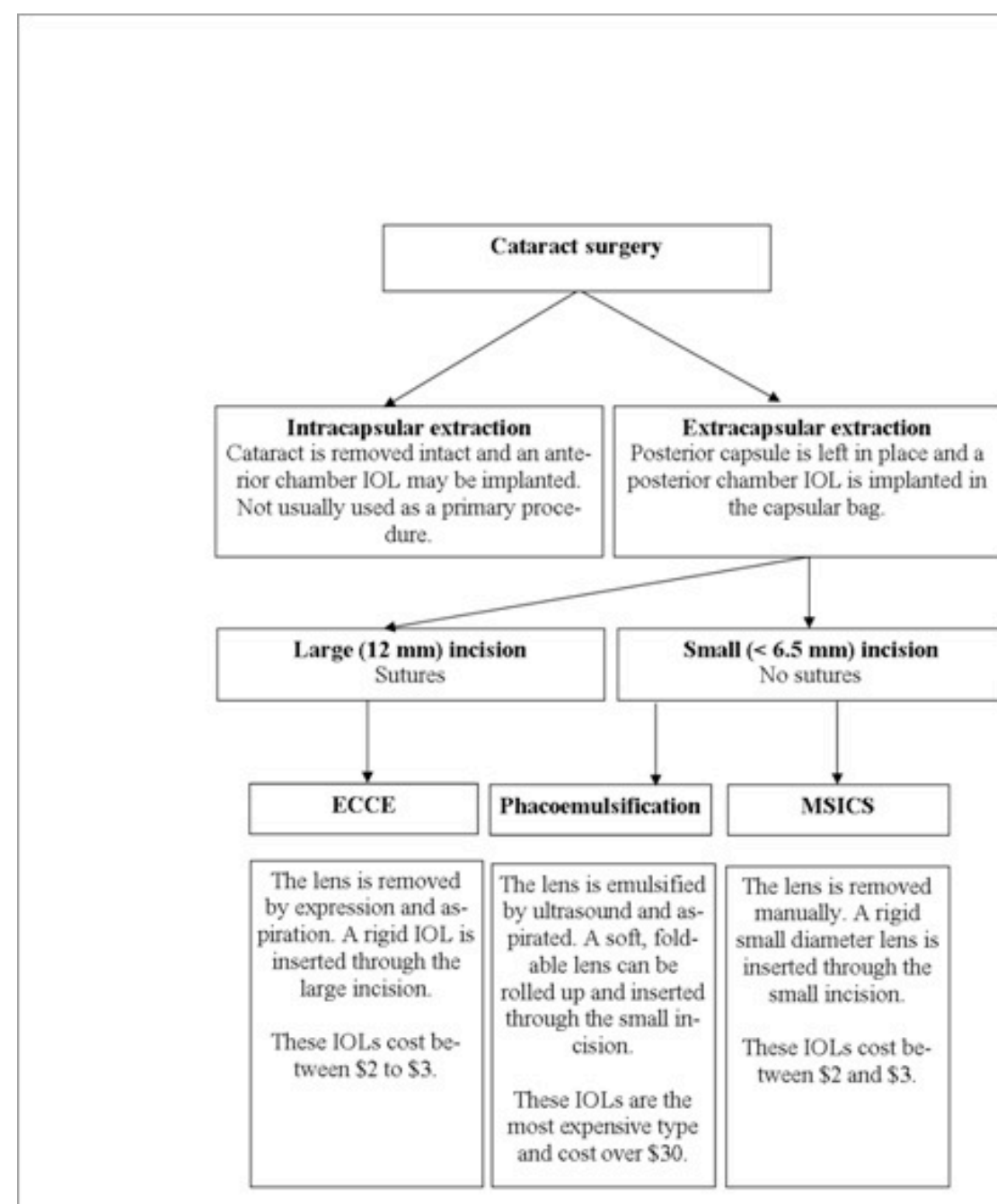

IOL: Intraocular lens

ECCE: Extracapsular cataract extraction

MSICS: Marual small incision surgery

Manual small incision cataract surgery (MSICS) with posterior chamber intraocular lens versus extracapsular cataract extraction 


\section{How the intervention might work}

Cataract surgery works by removing the opacified lens and replacing it with a clear lens called an IOL. IOLs can be made from a range of materials, and they can be made of varying size, shape and refractive powers. Before cataract surgery the eye to be operated on is measured so that an IOL of the correct power (strength) can be inserted after the cataract has been removed. The IOL is usually placed inside the "bag" of the lens capsule inside the eye. Other options for lens replacement include contact lenses and glasses.

Surgery is currently the only treatment option once the lens has opacified and vision is decreasing. The indication for surgery is based on whether the patient's reduced visual function interferes with their quality of life.

\section{Why it is important to do this review}

The World Health Organization (WHO) recently reported that age-related cataract is now responsible for $48 \%$ of world blindness, which represents about 18 million people currently. It was estimated that there were 37 million people worldwide who were blind in 2002 (Passolini 2004; Resnikoff 2004). Age-related cataract remains the leading cause of blindness globally, except in the most developed countries. This is despite an increasing number of visually impaired and blind people gaining access to cataract surgical services due to the development of prevention of blindness programmes in many countries (Kupfer 1994). Despite these positive trends the number of people blind due to cataract is increasing because of the changing demographic structure of populations (Limburg 1996; Minassian 1990; Thylefors 1998). More than $82 \%$ of all blind people are 50 years of age or older.

It is estimated that the present number of 20 million cataract blind will double by the year 2020. The global initiative "Vision 2020: The Right to Sight" has suggested various strategies to reduce cataract blindness (Foster 2001). The WHO has called for a dramatic increase in surgical volumes worldwide, but the outcomes of cataract surgery are not always good and may depend on the surgical technique used (Venkatesh 2005).

The first published version of this review 'Surgical interventions for age-related cataract' (Snellingen 2002) compared the outcomes of different cataract surgical techniques. The techniques included initially were intracapsular extraction (ICCE), ECCE and phacoemulsification. In 2006 the review was revised and a fourth surgical technique MSICS was added to the review (Riaz 2006).

Following consultation with the review authors and the Cochrane Eyes and Vision Group this update has been divided into three smaller reviews each using the same outcome measures but only comparing two surgical methods within each review. The ICCE technique is no longer included as this method is no longer used as a primary procedure.
The cataract surgical techniques compared in these three reviews are: 1. MSICS and ECCE (current review);

2. phacoemulsification and ECCE (Riaz 2010a);

3. phacoemulsification and MSICS (Riaz 2010b).

Although phacoemulsification is the most technologically advanced method providing small incision sutureless surgery, it requires considerable resources due to consumables, maintenance and training of surgeons. It is the procedure of choice for cataract surgery in developed countries.

From a global perspective phacoemulsification is too costly for many developing countries where there is the highest incidence of cataract blindness. Manual small incision surgery and ECCE are alternative techniques available at a lower cost. The aim of this review is to compare the relative effectiveness of ECCE and MSICS

This review will help to establish which surgical method (MSICS or ECCE) should be performed for people with age-related cataract, especially those living in low and middle-income countries, where high volumes of cataract surgeries are performed.

\section{O B J E C T I VES}

The aim of this review is to compare two different techniques of lens removal in cataract surgery: MSICS and ECCE.

\section{METHOD S}

\section{Criteria for considering studies for this review}

\section{Types of studies}

We included randomised controlled trials (RCTs) only.

\section{Types of participants}

Participants in the trials were people with age-related cataract.

\section{Types of interventions}

We included trials where MSICS with a posterior chamber IOL implant was compared to ECCE with a posterior chamber IOL implant.

We also considered the different ways in which the lens was removed in MSICS or ECCE. We defined these as:

- techniques requiring the placement of sutures;

Manual small incision cataract surgery (MSICS) with posterior chamber intraocular lens versus extracapsular cataract extraction 
- techniques not requiring the placement of sutures with the lens removed after manual fragmentation.

We did not consider phacoemulsification in this review as this is the subject of the two separate Cochrane reviews (Riaz 2010a; Riaz 2010b) mentioned above.

\section{Types of outcome measures}

\section{Primary outcomes}

The primary outcome for this review was postoperative visual acuity. We considered both presenting* and best-corrected visual acuity (BCVA) at the following cut-points.

- Proportion of people achieving good functional vision defined as presenting visual acuity better than or equal to $6 / 12$ in the operated eye.

- Proportion of people with a poor outcome after surgery defined as BCVA worse than 6/60 in the operated eye.

* Presenting visual acuity is vision that the person uses in normal life, i.e. with or without glasses, if worn.

\section{Secondary outcomes}

- Intraoperative complications

- capsular rupture with or without vitreous loss

$\circ$ iris prolapse

- postoperative inflammation

o other complications as reported

- Long-term complications (one year or more after surgery)

$\circ$ posterior capsule opacification

- retinal detachment

- glaucoma

- cystoid macular oedema

- corneal endothelial cell loss

- corneal decompensation

o other complications as reported

- Quality of life (self-care, mobility, social and mental

function) as reported

- Cost-effectiveness

\section{Follow up}

We considered outcomes at three months and one year after surgery. As studies may not report outcomes exactly at these time points we defined the following time periods:

- three months: from four weeks to less than six months

- 12 months: from six months to less than 18 months

\section{Search methods for identification of studies}

\section{Electronic searches}

We searched the Cochrane Central Register of Controlled Trials (CENTRAL) 2012, Issue 1, part of The Cochrane Library. www.thecochranelibrary.com (accessed 14 February 2012), MEDLINE (January 1950 to February 2012), EMBASE (January 1980 to February 2012), Latin American and Caribbean Literature on Health Sciences (LILACS) (January 1982 to February 2012), Web of Science Conference Proceedings Citation Index- Science (CPCI-S), the metaRegister of Controlled Trials ( $m$ RCT) (www.controlled-trials.com), ClinicalTrials.gov ( www.clinicaltrials.gov) and the WHO International Clinical Trials Registry Platform (ICTRP) (www.who.int/ictrp/search/en). There were no language or date restrictions in the search for trials. The electronic databases were last searched on 14 February 2012. See: Appendices for details of search strategies for CENTRAL (Appendix 1), MEDLINE (Appendix 2), EMBASE (Appendix 3), LILACS (Appendix 4), CPCI-S (Appendix 5), $m$ RCT (Appendix 6), ClinicalTrials.gov (Appendix 7) and the ICTRP (Appendix 8).

\section{Searching other resources}

We searched the reference lists of all included studies and pertinent reviews identified. We contacted the authors of the included studies to identify unpublished studies or studies sent for publication or in press.

\section{Data collection and analysis}

\section{Selection of studies}

Two authors assessed the search results for relevance and inclusion. We obtained full-text copies of any report referring to definitely or possibly relevant trials. We assessed these full-text copies according to the definitions in the 'Criteria for considering studies for this review' section. We only assessed trials meeting these criteria for methodological quality. Any trial that was excluded at this stage, was documented in the review and a reason for exclusion given.

\section{Data extraction and management}

We extracted data using a form developed by the Cochrane Eyes and Vision Group. Two authors extracted data and compared the results for differences. We resolved discrepancies by discussion. One author entered data in to Review Manager 5 (Review Manager 2011) and the second author checked for errors. 


\section{Assessment of risk of bias in included studies}

We assessed the included studies using the Cochrane Collaboration's tool for risk of bias as described in Chapter 8 of the Cochrane Handbook for Systematic Reviews of Interventions (Higgins 2011). We considered the following parameters: sequence generation and allocation concealment, masking (blinding) of participants, personnel and outcome assessors, incomplete outcome data, selective outcome reporting and other sources of bias. We graded them as low risk of bias, high risk of bias, and unclear risk of bias indicating either lack of information or uncertainty over the potential for bias. Two review authors independently assessed the risk of bias for each of these parameters and disagreement was resolved by discussion. Authors were not masked to the report authors and trial results during the assessment.

\section{Measures of treatment effect}

The outcomes for this review are largely dichotomous (i.e. postoperative visual acuity and complications). Our measure of treatment effect is the risk ratio. For outcomes that occur rarely (in less than $10 \%$ of the cohort), we planned to use the odds ratio. We planned to analyse quality of IIfe, which may be reported as a continuous variable, using the weighted mean difference, but in the event no data were available on quality of life.

\section{Unit of analysis issues}

The main unit of analysis issue is how the trial investigators dealt with the fact that people have two eyes. There are several options here: a trial may randomise people to the intervention groups and then apply the intervention and/or measure the outcome in one eye (study eye) or both eyes. In the latter case it is incorrect to analyse eyes without taking into account the fact that the eyes for a person are not independent. Alternatively a trial may randomly allocate eyes to an intervention so each person has a different intervention in each eye. In this case, the pairing has to be taken into account in the analysis. In our protocol we planned the following: At the review level, if the trial has been incorrectly analysed, we will contact the trial investigators for further information to enable calculation of a design effect (Perera 2007). If the trial does report estimates adjusted for within person correlation we will enter them in the review using the generic inverse variance method. Although cluster trials are a possibility we think they are unlikely because individual randomisation is relatively easy to do in this case.

However, we did not have enough data to include this in any formal meta-analysis. Only Gurung 2009 mentioned that 100 eyes of 88 participants were randomised into two groups. For the other two trials it was unclear from the study report but contact with the investigators of Gogate 2003 confirmed only one eye per person was entered into the trial.

\section{Dealing with missing data}

We planned to collect data on the reason for missingness, with the caveat that this might not be reliably reported.

Our plan to deal with missing data was as follows but in the event we did not have enough data for any formal meta-analysis:

Analyses based on available data assume that missing data are missing at random. We will investigate how reasonable this assumption is by doing a series of sensitivity analyses with different assumptions about the missing data using methods as set out by White et al (White 2008). The "informative missingness odds ratio" (IMOR) refers to the ratio of the odds of the outcome among participants for whom data are missing and the odds of the outcome among participants who are available. These IMORs can be assumed to be equal or different in the two trial arms. We plan to do four sensitivity analyses. Firstly we will assume the IMOR is 2 in treatment and control groups i.e. that people who were not seen were twice as likely to have the outcome. Secondly, we will assume that the IMOR was $1 / 2$ in both treatment and control groups i.e. that people who were not seen were half as likely to have the outcome. For the third and fourth sensitivity analyses, we will assume that the IMOR was opposite in treatment and control groups - i.e. 2 or $1 / 2$.

All analyses will be done using the metamiss command in Stata (version 11.0, StataCorp LP, 4905 Lakeway Drive, College Station, TX 77845 USA).

If the pooled risk ratio in any of these sensitivity analyses differs substantially from the available case analysis (say by $10 \%$ or more) it is likely that the missing data in the included trials are a cause for concern. We will record this information in the risk of bias tables under "incomplete data".

\section{Assessment of heterogeneity}

Our plan for assessing heterogeneity was as follows but in the event we did not have enough data for any formal meta-analysis:

We will assess heterogeneity in several ways. Firstly, by documenting clinical and methodological differences between the studies. Secondly by examining the forest plots to see whether the estimates of effect are consistent, and thirdly by considering the $I^{2}$ value and $\chi^{2}$ test for heterogeneity (bearing in mind that the $\chi^{2}$ test has low power when the number of trials is small).

\section{Assessment of reporting biases}

Our plan for assessing reporting biases was as follows but in the event we did not have enough data to complete these:

The main reporting biases that we will consider are publication bias and outcome reporting bias. For publication bias, if there are enough trials we will do a funnel plot to assess whether small trials have different effects. To assess outcome reporting bias we will complete a review outcome matrix following the ORBIT classification (Kirkham 2010). 


\section{Data synthesis}

Our plan for assessing data synthesis was as follows but in the event we did not have enough data for a formal meta-analysis:

We will pool data from studies collecting comparable outcome measures with similar follow-up times using a random-effects model (unless there are three or fewer trials in which case we will use a fixed-effect model). If there is evidence for substantial heterogeneity or inconsistency, for example an $I^{2}$ value of $50 \%$ or more, we will not pool the results.

The outcomes for this review include a number of complications. Initially we will tabulate these data only. For outcomes that are commonly reported we will go on to do a meta-analysis in order to provide a summary estimate of risk.

\section{Subgroup analysis and investigation of heterogeneity}

Our plan for subgroup analysis was as follows but in the event we did not have enough data for a formal subgroup analysis:

It is possible that the effect of the interventions will vary according to the setting (high/low volume) and whether or not suture/sutureless techniques are used. If there are enough data, we will explore heterogeneity focusing primarily on these subgroups.

\section{Sensitivity analysis}

Our plan for sensitivity analysis was as follows but in the event we did not have enough data for a formal sensitivity analysis:

If there are enough trials contributing to the meta-analyses we will investigate the effect of excluding poorer quality trials. In particular, we will investigate the effect of excluding trials where allocation concealment was not properly reported and where there was no masking of outcome assessment.

\section{RES U L T S}

\section{Description of studies}

See: Characteristics of included studies.

\section{Results of the search}

The electronic searches yielded a total of 148 titles and abstracts (Figure 2). After de-duplication we screened the title and abstracts of 103 references. We rejected 100 abstracts as not eligible for inclusion in the review. We obtained and screened full-text copies of three references and included them in the review. 
Figure 2. Results from searching for studies for inclusion in the review.

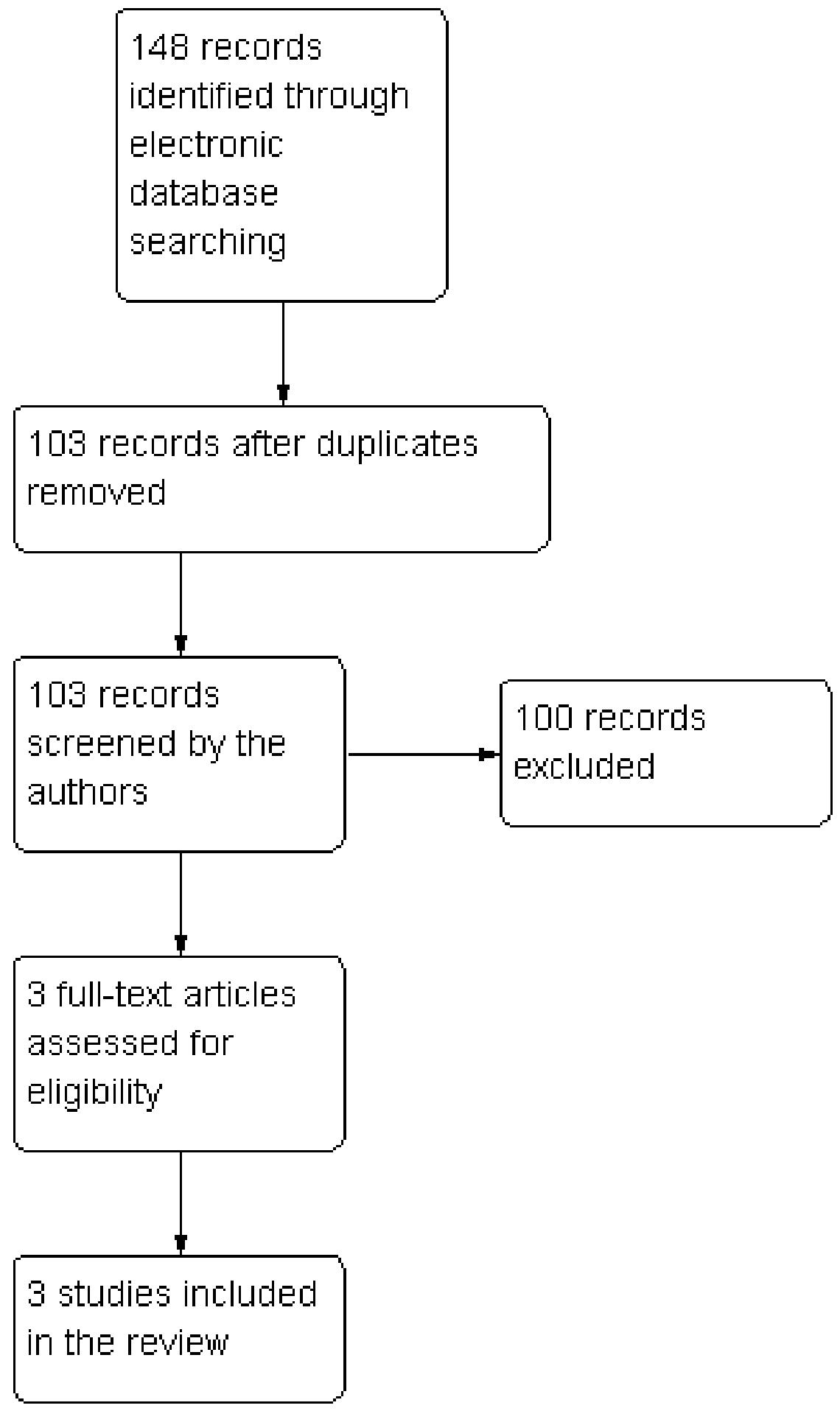




\section{Included studies}

We included three trials (George 2005; Gogate 2003; Gurung 2009) that met our inclusion criteria. We have provided a brief summary of the characteristics of the included studies and further details can be found in the 'Characteristics of included studies' table.

\section{Size of study}

Number of participants that underwent MSICS or ECCE were 124 (George 2005); 741 (Gogate 2003) and 88 (Gurung 2009) respectively.

\section{Location of studies}

Two studies were conducted in India (George 2005; Gogate 2003) and one in Nepal (Gurung 2009)

\section{Age of participants}

Participants were aged between 35 and 93 years of age. Specifically, the age of participants was a mean of $58 \pm 8.0$ years (George 2005); 40 to 90 years (Gogate 2003) and 35 to 93 years (Gurung 2009).

\section{Types of interventions}

All three studies compared MSICS with ECCE; in one trial there was an additional phacoemulsification arm (George 2005).

\section{Follow-up}

All three studies had a minimum follow-up of six weeks. None of the trials reported data after eight weeks. For Gogate 2003 this was confirmed by contact with the investigator.

\section{Outcomes}

All three studies evaluated visual acuity and astigmatism as their main outcome; and complications as part of results of the study. Distance visual acuity was measured in all trials using either Snellen acuity or LogMAR scale with the EDTRS chart. One study specifically stated their primary and secondary outcomes, such as surgical time and vision related quality of life, patient satisfaction, and economic outcomes. Postoperative complications were graded according to the Oxford Cataract Treatment and Evaluation Team (OCTET) grading system (OCTET 1986)

\section{Excluded studies}

We did not exclude any studies after obtaining full-text copies.

\section{Risk of bias in included studies}

See Figure 3 and Figure 4.

Figure 3. Risk of bias graph: review authors' judgements about each risk of bias item presented as percentages across all included studies.

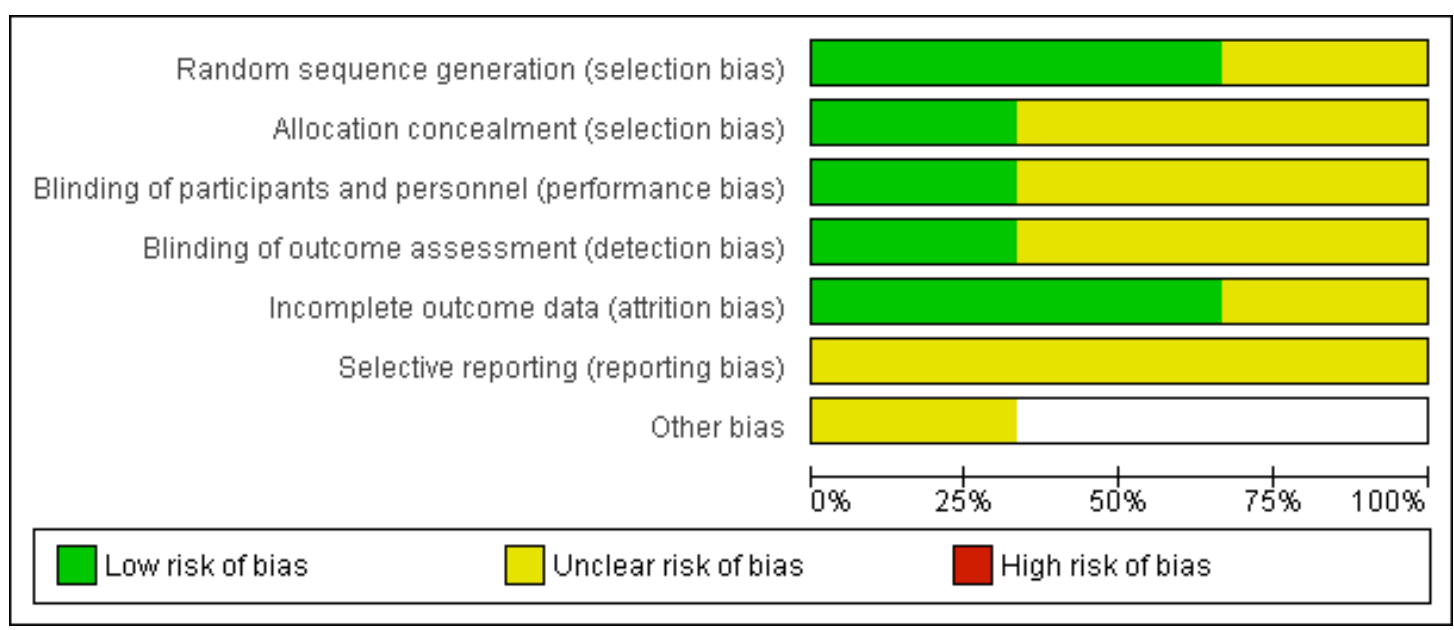

Manual small incision cataract surgery (MSICS) with posterior chamber intraocular lens versus extracapsular cataract extraction 
Figure 4. Risk of bias summary: review authors' judgements about each risk of bias item for each included study.

\begin{tabular}{|c|c|c|c|c|c|c|c|}
\hline & 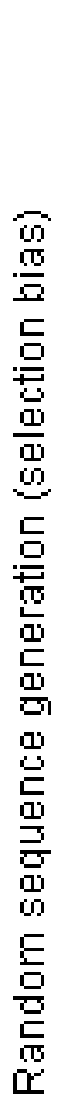 & 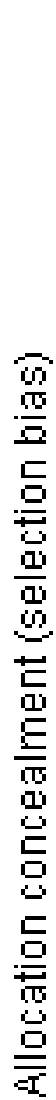 & 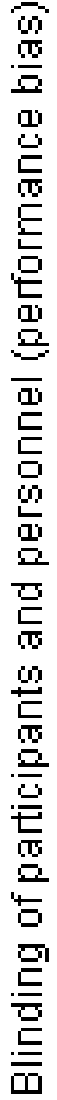 & 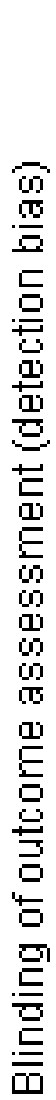 & 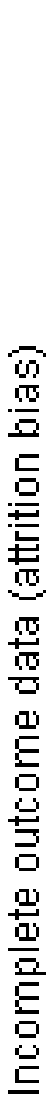 & 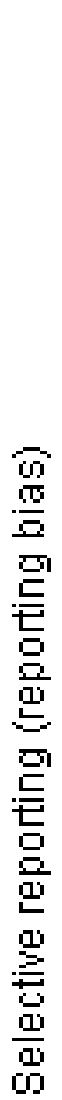 & 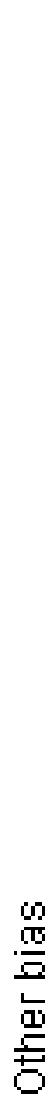 \\
\hline George 2005 & & $?$ & $?$ & $?$ & & $?$ & \\
\hline Gogate 2003 & & & & & & $?$ & $?$ \\
\hline Gurung 2009 & $?$ & $?$ & $?$ & $?$ & $?$ & $?$ & \\
\hline
\end{tabular}




\section{Allocation}

In only one trial was it clearly stated how the allocation schedule was generated (George 2005). One trial described using drawing lots or 'ballots' to randomly assign the treatment and surgeon (Gogate 2003). Allocation concealment was not described in any trial.

\section{Blinding}

In assessing ECCE and MSICS, it may be difficult to mask the assessors due to the obvious presence of sutures in ECCE. Nonetheless, masking was stated in one study where internee doctors and optometrists did postoperative visual acuity testing and administering the questionnaires; patients were not told about the type of surgery done (Gogate 2003).

\section{Incomplete outcome data}

Follow-up rates were good in all three trials: 85\% (George 2005); 95\% (Gogate 2003) and 100\% (Gurung 2009) respectively. Exclusions were not clearly documented except in one trial (Gogate 2003).

\section{Selective reporting}

Postoperative complications were not described in the George 2005 study. Otherwise, all outcomes on visual acuity, astigmatism and complications were reported in all three studies.

\section{Other potential sources of bias}

In one trial, some surgeons performed more surgeries of one kind to increase the external validity of the study. Imbalance of surgeon assignment may have introduced bias, but this was dealt with by stratification by surgeon in the analysis (Gogate 2003).

\section{Effects of interventions}

See: Summary of findings for the main comparison

\section{Visual outcomes}

The data on visual outcomes is summarised in Table 1 . The three studies only followed-up to six weeks (George 2005; Gogate 2003) and six to eight weeks (Gurung 2009).

In George 2005, 1/53 cases had BCVA < 6/18 in MSICS group compared to five in the ECCE group (three related to high astigmatism, one posterior capsule opacification and one anterior ischaemic optic neuropathy).
In the PUNE study (Gogate 2003),165/344 (48\%) of the MSICS group and 135/362 (37\%) of the ECCE group had a UCVA 6/ 18 or better (relative risk (RR) $1.29,95 \%$ confidence intervals (CI) 1.08 to 1.53$)$. Six (1.7\%) people in the MSICS group and four patients $(1.1 \%)$ in the ECCE group had poor visual outcome $(\mathrm{BCVA}<6 / 60)$ in the operated eye (RR $1.58,95 \%$ CI 0.45 to 5.55).

In Gurung 2009, UCVA of 6/12 and better was achieved in 17/ $50(34 \%)$ of the MSICS group and 7/50 (14\%) of people in the ECCE group (RR 2.43, 95\% CI 1.10 to 5.34) at six to eight weeks postoperatively.

\section{Surgically induced astigmatism (SIA)}

In George 2005, SIA was greater in the ECCE group compared to MSICS (mean induced astigmatism in dioptres, $1.77 \pm 1.65$ versus $1.1 \pm 0.95, P=0.012)$. In Gurung 2009, astigmatism of $\geq 2 \mathrm{D}$ was found in $17 / 48(35.4 \%)$ and $35 / 48(72.9 \%)$ participants from MSICS and ECCE groups respectively $(\mathrm{RR} 0.49,95 \% \mathrm{CI}=0.32$ to 0.74 ) at eight weeks. Surgically induced astigmatism was not described in the George 2005 study.

\section{Intraoperative surgical complications}

There were no reported complications during surgery in George 2005 and Gurung 2009. In the PUNE study (Gogate 2003), 21 of the patients in the MSICS group were converted to ECCE either due to density of cataract or because of small pupil. 29/358 (8.1\%) of the MSICS group and 17/383 (4.4\%) of the ECCE group and had intraoperative complications (RR 1.83, 95\% CI 1.02 to 3.26). $18 / 358$ (six with vitreous loss) in the MSICS group had posterior capsule tears compared to $10 / 383$ (six with vitreous loss) in the ECCE group (RR 1.93, 95\% CI 0.90 to 4.12). Two patients in the MSICS group had iridodialysis.

\section{Postoperative complications}

Postoperative complications were not described in George 2005. In Gurung 2009, corneal oedema was present immediately postoperatively in $48 \%$ of MSICS and 62\% in ECCE, which cleared by eight weeks postoperatively. One patient from MSICS group had Descemet membrane detachment that reattached by eight weeks with good vision. Posterior capsule opacification was present in $6 \%$ of MSICS and 4\% of ECCE. In the PUNE study (Gogate 2003), $121 / 358(33.8 \%)$ of the MSICS group and 94/383 (24.5\%) of the ECCE group had postoperative complications in the first six weeks (RR $1.38,95 \%$ CI 1.10 to 1.73 ); the majority were mild (27.1\%) (OCTET grade 1). There were no severe complications (OCTET grade 3), moderate complications were seen in $5 / 358$ 
in the MSICS group and 3/383 ECCE group (RR 1.78, 95\% CI 0.43 to 7.41 ), there was no significant difference between the two groups. Mild complications e.g. Descemet's folds, iritis and corneal oedema were more commonly seen in the MSICS group (32.4\% versus $23.7 \%$ ECCE group). Posterior capsule opacification was seen equally in both groups (4/358 MSICS versus 3/383 ECCE).

\section{Endothelial cell count}

Gogate 2003 and Gurung 2009 did not study this outcome. In George 2005, there was no statistically significant difference in endothelial cell loss between the MSICS and ECCE groups. The sample size was adequate to detect a $7 \%$ difference in endothelial cell count between the groups, giving a power of $80 \%$. There was a mean $4.72 \%(\mathrm{~N}=52, \mathrm{SD} 13.07)$ induced cell loss in ECCE at six weeks follow-up compared with $4.21 \%(\mathrm{~N}=53$, SD 10.29) for MSICS.

\section{Economic evaluation}

In the PUNE study (Gogate 2003), there was no significant difference in surgical time or cost between the two procedures, even accounting for surgeon variation. The average cost of ECCE was USD 15.82, MSICS USD 15.68 of which USD 11.34 was a fixed facility cost common to both.

\section{DISCUSSION}

\section{Summary of main results}

Overall, visual outcomes are comparable between MSICS and ECCE ('Summary of findings for the main comparison'). Although MSICS have better UCVA results, there is no difference in BCVA between the two methods. However, surgically induced astigmatism is significantly greater after ECCE compared to MSICS. There is suggestion that there are fewer intraoperative and postoperative complications after ECCE than MSICS but this requires further study based on the quality of evidence supporting this. Thus, in countries such as India where high surgical volumes are required, MSICS was suggested to be the surgical technique of choice due to better unaided visual outcomes but equal costs.

\section{Overall completeness and applicability of evidence}

As most study participants came from India or Nepal, the applicability to other populations or races may be limited. Moreover, within India there is a difference between the results from hospitals when compared to cataract camps (Singh 2000), which should be kept in mind when interpreting these results. Furthermore, evaluation of cataract surgery outcomes should not be based on postoperative visual acuity alone - and assessments of quality of life and quality of vision should be made. The studies in this review did not specifically measure these outcomes.

\section{Quality of the evidence}

We included three trials in this review, which compared two techniques for cataract surgery. Due to the small number of studies that actually examined our objectives, conclusions have to be interpreted with caution. The main outcome measure was visual acuity in the studies reviewed. However, it is not appropriate to compare MSICS and ECCE at six weeks, as suture techniques such as ECCE require a longer period for vision stabilisation due to suture induced astigmatism. Only one study had a follow-up of up to one year (Gogate 2003) but did not report these data. Although long-term follow-up is always a challenge in developing countries, more studies with a longer-follow-up are required.

\section{Potential biases in the review process}

All studies included were from an extensive search with the abovementioned search and inclusion criteria. However, only three studies were included out of the many studies reviewed. Studies not published and indexed in the libraries included, or non-English journals may have been omitted. While RCTs provide the highest level of evidence, cohort studies or observational studies could provide some information not included in this review. Finally, publication bias may exist if only studies with significant results are published, however, we did not have direct evidence of any publication bias in this case.

\section{Agreements and disagreements with other studies or reviews}

When evaluating cataract surgeries, cost-effectiveness is an important outcome measure not studied frequently. In our review, included studies suggested that MSICS had better unaided visual acuity and equal cost. Another study not included in this review found that MSICS (USD 17.03) cost more than ECCE (USD 16.25) (Muralikrishnan 2004), but patients' costs (direct and indirect) were highest for ECCE due to the increased number of days required for follow-up, which incurs transportation and economic productivity loss. However, it is unclear if this study was adequately powered to study this and clearly, the need for a proper cost-effectiveness study is required. 


\section{AUTHORS' CONCLUSIONS}

\section{Implications for practice}

This review, which only includes three RCTs, suggests that MSICS gives better uncorrected visual acuity and less surgically induced astigmatism compared to ECCE. Each surgical technique has its limitations, and should be chosen based on patients' medical and ocular history. For example, relative contraindications to MSICS include zonular weakness, lack of corneal clarity with corneal decompensation and dense cataracts. There are no other studies from other countries other than India and Nepal and there are insufficient data on cost-effectiveness of each procedure. Better evidence is needed before any change may be implemented.

\section{Implications for research}

More studies are required to compare the visual outcomes between MSICS and ECCE. We suggest that visual outcomes at three and six months are the minimum follow-up time for comparing ECCE and MSICS. Also, an adequately powered randomised controlled trial is required to assess cost-effectiveness and the impact on quality of life. When executing these RCTs the study participant should be randomised to expert surgeons in each technique rather than having the same surgeon performing both procedures to reduce single surgeon bias. A single surgeon performing both procedures does not produce a surgeon effect. This is bias introduced by a surgeon having more expertise in one intervention as compared to the other.

\section{ACKNOW LEDGEMENTS}

The Cochrane Eyes and Vision Group (CEVG) Trials Search Coordinator created and ran the electronic search strategies. We thank Clare Gilbert, Catey Bunce and Richard Wormald for their comments on the review and Anupa Shah for editorial support.

Richard Wormald (Co-ordinating Editor for CEVG) acknowledges financial support for his CEVG research sessions from the Department of Health through the award made by the National Institute for Health Research to Moorfields Eye Hospital NHS Foundation Trust and UCL Institute of Ophthalmology for a Specialist Biomedical Research Centre for Ophthalmology. The views expressed in this publication are those of the authors and not necessarily those of the Department of Health.

\section{RE F E R E N C E S}

\section{References to studies included in this review}

George 2005 \{published data only\}

George R, Rupauliha P, Sripriya AV, Rajesh PS, Vahan PV, Praveen S. Comparison of endothelial cell loss and surgically induced astigmatism following conventional extracapsular cataract surgery, manual small-incision surgery and phacoemulsification. Ophthalmic Epidemiology 2005; 12(5):293-7.

Gogate 2003 \{published data only\}

Gogate PM, Deshpande M, Wormald RP, Deshpande R, Kulkarni SR. Extracapsular cataract surgery compared with manual small incision cataract surgery in community eye care setting in western India: a randomised controlled trial. British Journal of Ophthalmology 2003;87(6):667-72.

Gurung 2009 \{published data only\}

Gurung A, Karki DB, Shrestha S, Rijal AP. Visual outcome of conventional extracapsular cataract extraction with posterior chamber intraocular lens implantation versus manual small-incision cataract surgery. Nepalese Journal of Ophthalmology 2009;1(1):13-9.

\section{Additional references}

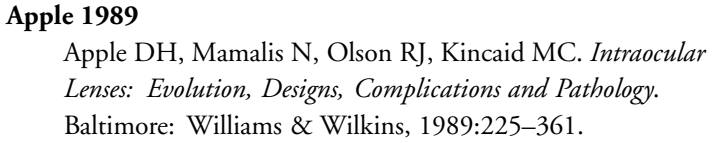

\section{Apple 1992}

Apple DJ, Solomon KD, Tetz MR, Assia EI, Holland EY, Legler UF, et al.Posterior capsule opacification. Survey of Ophthalmology 1992;37(2):73-116.

Blumenthal 1992

Blumenthal M, Ashkenazi I, Assia E, Cahane M. Smallincision manual extracapsular cataract extraction using selective hydrodissection. Ophthalmic Surgery 1992;23(10): 699-701.

Duane 1986

Duane T. Textbook of Ophthalmology. Lippincott-Raven, 1986:25.

Foster 2001

Foster A. Cataract and "Vision 2020-the right to sight" initiative. British Journal of Ophthalmology 2001;85(6): 635-7.

Glanville 2006 Glanville JM, Lefebvre C, Miles JN, Camosso-Stefinovic J. How to identify randomized controlled trials in MEDLINE: ten years on. Journal of the Medical Library Association 2006; 94(2):130-6.

Gogate 2005

Gogate PM, Kulkarni SR, Krishnaiah S, Deshpande RD, Joshi SA, Palimkar A, et al.Safety and efficacy of phacoemulsification compared with manual small-incision cataract surgery by a randomized controlled clinical trial: six-week results. Ophthalmology 2005;112(5):869-74. 


\section{Hennig 1999}

Hennig A. Tunnel sutureless high volume cataract surgery. IAPB 6th General Assembly. Beijing, September 61999.

\section{Higgins 2011}

Higgins JPT, Altman DG, Sterne JAC (editors). Chapter 8: Assessing risk of bias in included studies. In: Higgins JPT, Green S (editors). Cochrane Handbook for Systematic Reviews of Interventions Version 5.1.0 (updated March 2011). The Cochrane Collaboration, 2011. Available from www.cochrane-handbook.org.

\section{Javitt 1992}

Javitt JC, Tielch JM, Canner JK, Kolb MM, Sommer A, Steinberg EP. National outcomes of cataract extraction. Increased risk of retinal complications associated with $\mathrm{Nd}$ : YAG laser capsulotomy. The Cataract Patient Outcomes Research Team. Ophthalmology 1992;99(10):1487-98.

Kirkham 2010

Kirkham JJ, Dwan KM, Altman DG, Gamble C, Dodd $S$, Smyth R, et al.The impact of outcome reporting bias in randomised controlled trials on a cohort of systematic reviews. BMJ 2010;340:c365.

\section{Kupfer 1994}

Kupfer C. The International Agency for the Prevention of Blindness. American Journal of Ophthalmology 1994;117(2): 253-7.

\section{Limburg 1996}

Limburg H, Kumar R, Bachani D. Monitoring and evaluating cataract intervention in India. British Journal of Ophthalmology 1996;80(11):951-5.

\section{Mehta 1999}

Mehta KR, Mehta CK. Teaching standards in phacoemulsification. How realistic are they?. Symposium on Phacoemulsification. VI Ophthalmological Congress of SAARC Countries. Kathmandu, November 201999.

\section{Minassian 1990}

Minassian DC, Mehra V. 3.8 Million blinded by cataract each year: projections from the first epidemiological study of the incidence of cataract blindness in India. British Journal of Ophthalmology 1990;74(6):341-3.

Muralikrishnan 2004

Muralikrishnan R, Venkatesh R, Prajna NV, Frick KD. Economic cost of cataract surgery procedures in an established eye care centre in Southern India. Ophthalmic Epidemiology 2004;11(5):369-80.

Norregaard 1999

Norregaard JC, Bernth-Pettersen P, Bellan L, Alonso J, Black C, Dunn E, et al.Intraoperative clinical practice and risk of early complications after cataract extraction in the Unites States, Canada, Denmark and Spain. Ophthalmology 1999;106(1):42-8.

\section{OCTET 1986}

Anonymous. Use of a grading system in the evaluation of complications in a randomised controlled trial on cataract surgery. Oxford Cataract Treatment and Evaluation Team
(OCTET). British Journal of Ophthalmology 1986;70(6):

$411-4$.

\section{Passolini 2004}

Passolini D, Mariotti SP, Pokharel GP, Pararajasegarm R, Etyalale D, Negrel AD, et al.2002 global update of available data on visual impairment:a compilation of populationbased prevalence studies. Ophthalmic Epidemiology 2004;11 (2):67-115.

\section{Perera 2007}

Perera R, Glasziou P. A simple method to correct for the design effect in systematic reviews of trials using paired dichotomous data. Journal of Clinical Epidemiology 2007; 60(9):975-8.

\section{Resnikoff 2004}

Resnikoff S, Passolini D, Etyalale D, Kocur I, Pararajasegarm R, Pokharel GP, et al.Global data on visual impairment in the year 2002. Bulletin of The World Health Organisation 2004;82(11):844-51.

\section{Review Manager 2011}

The Nordic Cochrane Centre, The Cochrane Collaboration. Review Manager (RevMan). 5.1. Copenhagen: The Nordic Cochrane Centre, The Cochrane Collaboration, 2011.

Riaz 2006

Riaz Y, Mehta JS, Wormald R, Evans JR, Foster A, Ravilla

$\mathrm{T}$, et al.Surgical interventions for age-related cataract. Cochrane Database of Systematic Reviews 2006, Issue 4. [DOI: 10.1002/14651858.CD001323.pub2]

\section{Riaz 2010a}

Riaz Y, Malik A, Evans JR. Phacoemulsification with posterior chamber intraocular lens versus extracapsular cataract extraction (ECCE) with posterior chamber intraocular lens for age-related cataract. Cochrane Database of Systematic Reviews 2010, Issue 11. [DOI: 10.1002/ 14651858.CD008812]

Riaz 2010b

Riaz Y, Malik A, Evans JR. Phacoemulsification with posterior chamber intraocular lens versus manual small incision cataract surgery with posterior chamber intraocular lens for age-related cataract. Cochrane Database of Systematic Reviews 2010, Issue 11. [DOI: 10.1002/ 14651858.CD008813]

\section{Ruit 2000}

Ruit S, Paudyal G, Gurung R, Tabin G, Moran D, Brian G. An innovation in developing world cataract surgery: sutureless extracapsular cataract extraction with intraocular lens implantation. Clinial and Experimental Ophthalmology 2000;28(4):274-9.

Singh 2000 Singh AJ, Garner P, Floyd K. Cost-effectiveness of publicfunded options for cataract surgery in Mysore, India. Lancet 2000;355(9199):180-4.

\section{Snellingen 2002}

Snellingen T, Evans JR, Ravilla T, Foster A. Surgical interventions for age-related cataract. Cochrane Database 
of Systematic Reviews 2002, Issue 2. [DOI: 10.1002/ 14651858.CD001323]

\section{Thylefors 1998}

Thylefors B. A global initiative for the elimination of avoidable blindness. American Journal of Ophthalmology 1998;125(1):90-3.

\section{Venkatesh 2005}

Venkatesh R, Muralikrishnan, Balent LC, Prakash SK,

Prajna NV. Outcomes of high volume cataract surgeries in a developing country. British Journal of Ophthalmology 2005; 89(9):1079-83.

\section{White 2008}

White IR, Higgins JP, Wood AM. Allowing for uncertainty due to missing data in meta-analysis-Part 1: two-stage methods. Statistics in Medicine 2008;27(5):711-27.

\section{Yorston 2005}

Yorston D. High-volume surgery in developing countries. Eye 2005;19(10):1083-9.

* Indicates the major publication for the study 


\section{CHARACTERISTICS OF STUDIES}

\section{Characteristics of included studies [ordered by study ID]}

\section{George 2005}

Methods

Participants
Randomised controlled trial

Masking of outcome assessment: not reported. ECCE: sutured; PHACO and MSICS: not routinely sutured unless wound leak

Number randomised: 186 patients (total)

Number of patients underwent ECCE: 62

Number of patients underwent MSICS: 62

Age:

Mean age of ECCE group: $57.8 \pm 8.0$ years

Mean age of MSICS group: $58.8 \pm 8.7$ years

Inclusion criteria: patient undergoing planned cataract surgery; otherwise normal preop examination; cataract < grade III

Exclusion criteria: other potential causes of decreased vision; complicated cataracts; non age-related cataracts; phacodenesis; glaucoma or retinal pathology

Country: India

PHACO versus ECCE versus MSICS

Follow-up: six weeks

SIA; EC - specular microscopy counts; visual acuity

Outcomes

Two surgeons

PHACO - $5 \mathrm{~mm}$ incision rigid lens

MSICS - Blumenthal technique

\section{Risk of bias}

\begin{tabular}{|c|c|c|}
\hline Bias & Authors' judgement & Support for judgement \\
\hline $\begin{array}{l}\text { Random sequence generation (selection } \\
\text { bias) }\end{array}$ & Low risk & $\begin{array}{l}\text { "Cases were randomized into three groups } \\
\text { based on computer-generated random num- } \\
\text { bers. Randomization was carried out at the } \\
\text { time of admission and used the hospital num- } \\
\text { bers (which were allotted at the time of the } \\
\text { firsthospital visit) for allocation into different } \\
\text { groups." Page } 294 \\
\text { "Cases were separately randomized for each } \\
\text { surgeon so that equal numbers of each tech- } \\
\text { nique were performed by each surgeon". Page } \\
294\end{array}$ \\
\hline
\end{tabular}

Allocation concealment (selection bias) Unclear risk $\quad$ Not stated 


\section{George 2005 (Continued)}

\begin{tabular}{|c|c|c|}
\hline $\begin{array}{l}\text { Blinding of participants and personnel } \\
\text { (performance bias) } \\
\text { All outcomes }\end{array}$ & Unclear risk & Not stated \\
\hline $\begin{array}{l}\text { Blinding of outcome assessment (detection } \\
\text { bias) } \\
\text { All outcomes }\end{array}$ & Unclear risk & Not stated \\
\hline $\begin{array}{l}\text { Incomplete outcome data (attrition bias) } \\
\text { All outcomes }\end{array}$ & Low risk & $\begin{array}{l}\text { The } 6 \text {-weeks follow-up was completed by } \\
52 / 62 \text { cases of ECCE, } 53 / 62 \text { cases of SICS }\end{array}$ \\
\hline Selective reporting (reporting bias) & Unclear risk & $\begin{array}{l}\text { There were no intra-operative compli- } \\
\text { cations and post-operative complications } \\
\text { were not described. Authors presented } \\
\text { main outcomes, visual acuity, astigmatism } \\
\text { and endothelial cell counts as described }\end{array}$ \\
\hline
\end{tabular}

\section{Gogate 2003}

\begin{tabular}{ll}
\hline Methods & Randomised clinical trial: ECCE and MSICS \\
\hline Participants & 741 patients \\
Age: 40 to 90 years & $\begin{array}{l}\text { Inclusion criteria: cataract patients within age } 40 \text { to } 90 \text { years old } \\
\text { Exclusion criteria: any ocular co-morbidity capable of compromising vision, if they } \\
\text { needed combined surgical procedures, or if the axial length of the eye was more than } 26 \\
\text { mm }\end{array}$ \\
\hline Interventions & $\begin{array}{l}\text { ECCE versus MSICS } \\
\text { Follow-up: one week, six weeks, and one year after surgery }\end{array}$ \\
\hline Outcomes & $\begin{array}{l}\text { Visual acuity } \\
\text { Primary outcome was the proportion of patients having uncorrected and corrected visual } \\
\text { acuity of } 6 / 18 \text { or better at } 6 \text { weeks by both techniques } \\
\text { Secondary outcomes: } \\
1 . \text { Complications, both intraoperative and postoperative, with either technique } \\
\text { 2. The average surgical time for each technique } \\
\text { 3. Vision related quality of life, patient satisfaction, and economic outcomes }\end{array}$ \\
\hline Randomisation and blinding/masking of outcome assessment clearly described in Meth- \\
ods
\end{tabular}

\section{Risk of bias}

\begin{tabular}{|c|c|c|}
\hline Bias & Authors' judgement & Support for judgement \\
\hline $\begin{array}{l}\text { Random sequence generation (selection } \\
\text { bias) }\end{array}$ & Low risk & $\begin{array}{l}\text { "Each patient was randomly allocated to one } \\
\text { of the two groups by drawing lots (ballots). }\end{array}$ \\
\hline
\end{tabular}


Gogate 2003 (Continued)

There was always a 50\% chance of the patient getting one particular kind of intervention." Page 669

Allocation concealment (selection bias) Low risk
"The operating surgeons also drew ballots for the type of surgery they were supposed to do that day, at the beginning of the theatre list immediately before scrubbing. This random assignment was done in the presence of the anaesthetist, operation theatre senior nurse, and another non-operating ophthalmologist. " Page 669
Blinding of participants and personnel Low risk (performance bias)

All outcomes
"The patients were not informed as to the type of intervention they would receive, in the $O T$ and during follow up. The surgeons were unaware until scrubbing up which surgery they would perform that day. They were also unaware which patient would be brought to them for surgery and did not examine the patients the next day." Page 669

"Internee doctors and optometrists did postoperative visual acuity testing and administering the questionnaires. They were not told about the type of surgery done. " Page 669

706/741 completed follow-up. ECCE group 362/383 (94.5\%) and MSICS group $344 / 358$ (96.1\%). Figure 1 page 668

None obvious

Some surgeons performed more surgeries of one kind if the operating list was more compared to the other technique when the list was shorter. This was done to increase the external validity of the study. Imbalance of surgeon assignment may have introduced bias, but this was dealt with by stratification by surgeon in the analysis 


\begin{tabular}{|c|c|c|}
\hline Methods & \multicolumn{2}{|c|}{ Randomised clinical trial, 2 arms: ECCE and MSICS } \\
\hline Participants & \multicolumn{2}{|c|}{$\begin{array}{l}100 \text { eyes ( } 88 \text { patients) } \\
\text { Age: } 35 \text { to } 93 \text { years } \\
\text { Inclusion criteria: cataract patients with no local or systemic diseases } \\
\text { Exclusion criteria: any ocular co-morbidity capable of compromising vision, e.g., patients } \\
\text { with central corneal opacity, glaucoma, diabetics with significant fundus changes, patients } \\
\text { with inflammatory eye diseases, etc }\end{array}$} \\
\hline Interventions & \multicolumn{2}{|c|}{$\begin{array}{l}\text { ECCE versus MSICS } \\
\text { Follow-up: six to eight weeks }\end{array}$} \\
\hline Outcomes & \multicolumn{2}{|c|}{ Unaided and best-corrected visual acuity and astigmatism } \\
\hline Notes & \multicolumn{2}{|c|}{$\begin{array}{l}\text { Masking of outcome assessment: not reported. } \\
\text { Analysed } 100 \text { eyes of } 88 \text { patients; did not adjust for within-patient correlation }\end{array}$} \\
\hline \multicolumn{3}{|l|}{ Risk of bias } \\
\hline Bias & Authors' judgement & Support for judgement \\
\hline $\begin{array}{l}\text { Random sequence generation (selection } \\
\text { bias) }\end{array}$ & Unclear risk & $\begin{array}{l}\text { Used "systematic randomization sampling } \\
\text { technique" for allocation into two groups. } \\
\text { Page } 14\end{array}$ \\
\hline Allocation concealment (selection bias) & Unclear risk & Not stated \\
\hline $\begin{array}{l}\text { Blinding of participants and personnel } \\
\text { (performance bias) } \\
\text { All outcomes }\end{array}$ & Unclear risk & Not stated \\
\hline $\begin{array}{l}\text { Blinding of outcome assessment (detection } \\
\text { bias) } \\
\text { All outcomes }\end{array}$ & Unclear risk & $\begin{array}{l}\text { Not stated. At the end of six to eight } \\
\text { weeks, the final unaided visual acuity was } \\
\text { recorded. The best-corrected visual acuity } \\
\text { with the type of astigmatism was noted by } \\
\text { objective and subjective refraction }\end{array}$ \\
\hline $\begin{array}{l}\text { Incomplete outcome data (attrition bias) } \\
\text { All outcomes }\end{array}$ & Unclear risk & All participants completed follow-up \\
\hline Selective reporting (reporting bias) & Unclear risk & None obvious \\
\hline
\end{tabular}

ECCE: extracapsular extraction

MSICS: manual small incision cataract surgery

PHACO: phacoemulsification

SIA: surgically induced astigmatism 


\section{DATA AND ANALYSES}

This review has no analyses.

\section{A D D I T IONAL TABLES}

Table 1. Visual acuity

\begin{tabular}{|c|c|c|c|c|c|c|}
\hline \multirow[t]{2}{*}{ Outcome } & \multicolumn{3}{|c|}{ *3 months } & \multicolumn{3}{|c|}{12 months } \\
\hline & $\begin{array}{l}\text { MSICS } \\
\mathrm{n} / \mathrm{N}\end{array}$ & $\begin{array}{l}\text { ECCE } \\
\mathrm{n} / \mathrm{N}\end{array}$ & $\begin{array}{l}{ }^{* * *} \text { Risk ratio }(95 \% \\
\mathrm{CI})\end{array}$ & $\begin{array}{l}\text { MSICS } \\
\mathrm{n} / \mathrm{N}\end{array}$ & $\begin{array}{l}\text { ECCE } \\
\mathrm{n} / \mathrm{N}\end{array}$ & Risk ratio $(95 \% \mathrm{CI})$ \\
\hline \multicolumn{7}{|c|}{ **Presenting vision $6 / 12$ or better } \\
\hline George 2005 & \multicolumn{3}{|l|}{ No data } & \multicolumn{3}{|l|}{ No data } \\
\hline Gogate 2003 & $165 / 344$ & $135 / 362$ & $1.29(1.08$ to 1.53$)$ & \multicolumn{3}{|l|}{ No data } \\
\hline Gurung 2009 & $17 / 50$ & $7 / 50$ & $2.43(1.10$ to 5.34$)$ & \multicolumn{3}{|l|}{ No data } \\
\hline \multicolumn{7}{|l|}{$\mathrm{BCVA}<6 / 60$} \\
\hline George 2005 & \multicolumn{3}{|l|}{ No data } & \multicolumn{3}{|l|}{ No data } \\
\hline Gogate 2003 & $6 / 344$ & $4 / 362$ & $1.58(0.45$ to 5.55$)$ & \multicolumn{3}{|l|}{ No data } \\
\hline Gurung 2009 & $0 / 50$ & $0 / 50$ & & \multicolumn{3}{|l|}{ No data } \\
\hline
\end{tabular}

BCVA: best-corrected visual acuity

* In the protocol for the review we planned to measure outcomes at three months which we defined as any assessment between 4 weeks and 6 months. In fact both trials contributing data measured visual acuity a bit earlier than 3 months at six weeks (Gogate 2003) and six to eight weeks (Gurung 2009).

** In the protocol for the review, we planned to examine "presenting" vision but in fact both trials reported unaided or uncorrected vision here and Gogate 2003 only reported visual acuity of $6 / 18$ or better.

*** Data from Gogate 2003; Gurung 2009 were inconsistent $\left(\mathrm{I}^{2}=59 \%\right)$ therefore were not pooled. 


\section{A P P E N D I C E S}

\section{Appendix I. CENTRAL search strategy}

\#1 MeSH descriptor Cataract

\#2 MeSH descriptor Cataract Extraction

\#3 MeSH descriptor Lens, Crystalline

\#4 MeSH descriptor Lenses, Intraocular

\#5 MeSH descriptor Lens Implantation, Intraocular

\#6 intraocular lens* or intra ocular lens* or IOL*

\#7 (\#1 OR \#2 OR \#3 OR \#4 OR \#5 OR \#6)

\#8 extracapsular near/2 cataract*

\#9 extra capsular near/2 cataract*

\#10 ECCE

\#11 (\#8 OR \#9 OR \#10)

\#12 manual near/3 small near/3 incision near/3 cataract*

\#13 MISICS or SICS

\#14 MeSH descriptor Capsulorhexis

\#15 continuous near/3 curvilinear near/3 capsulor*hexis

\#16 continuous near/3 circular near/3 capsulor*hexis

\#17 CCC or CCS

\#18 can opener near/5 capsulotom*

\#19 endocapsular

\#20 (\#12 OR \#13 OR \#14 OR \#15 OR \#16 OR \#17 OR \#18 OR \#19)

\#21 (\#7 AND \#11 AND \#20)

\section{Appendix 2. MEDLINE (OvidSP) search strategy}

1. randomized controlled trial.pt.

2. (randomized or randomised).ab,ti.

3. placebo.ab,ti.

4. dt.fs.

5. randomly.ab,ti.

6. trial.ab,ti.

7. groups.ab,ti.

8. or/1-7

9. $\exp$ animals/

10. exp humans/

11. 9 not (9 and 10)

12. 8 not 11

13. exp cataract/

14. cataract extraction/

15. exp lens crystalline/

16. exp lenses intraocular/

17. lens implantation intraocular/

18. (intraocular lens\$ or intra ocular lens\$ or IOL\$).tw.

19. or/13-18

20. (extracapsular adj2 cataract\$).tw.

21. (extra capsular adj2 cataract\$).tw.

22. ECCE.tw.

23. or/20-22

24. (manual adj3 small adj3 incision adj3 cataract\$).tw.

25. (MISICS or SICS).tw.

Manual small incision cataract surgery (MSICS) with posterior chamber intraocular lens versus extracapsular cataract extraction 
26. capsulorhexis/

27. (continuous adj3 curvilinear adj3 capsulor?hexis).tw.

28. (continuous adj3 circular adj3 capsulor?hexis).tw.

29. (CCC or CCS).tw.

30. (can opener adj5 capsulotom\$).tw.

31. endocapsular.tw.

32. or/24-31

33.19 and 23 and 32

34.12 and 33

The search filter for trials at the beginning of the MEDLINE strategy is from the published paper by Glanville et al (Glanville 2006).

\section{Appendix 3. EMBASE (OvidSP) search strategy}

1. exp randomized controlled trial/

2. exp randomization/

3. exp double blind procedure/

4. exp single blind procedure/

5. random\$.tw.

6. or/1-5

7. (animal or animal experiment).sh.

8. human.sh.

9.7 and 8

10. 7 not 9

11.6 not 10

12. exp clinical trial/

13. (clin\$ adj3 trial\$).tw.

14. ((singl\$ or doubl\$ or trebl\$ or tripl\$) adj3 (blind\$ or mask\$)).tw.

15. exp placebo/

16. placebo $\$ . t w$.

17. random\$.tw.

18. exp experimental design/

19. exp crossover procedure/

20. exp control group/

21. exp latin square design/

22. or/ $12-21$

23. 22 not 10

24. 23 not 11

25. exp comparative study/

26. exp evaluation/

27. exp prospective study/

28. (control\$ or prospectiv\$ or volunteer $\$$ ).tw.

29. or $/ 25-28$

30. 29 not 10

31.30 not (11 or 23$)$

32. 11 or 24 or 31

33. exp cataract/

34. exp cataract extraction/

35. exp lens/

36. exp lens implant/

37. exp lens implantation/

38. (intraocular lens\$ or intra ocular lens\$ or IOLS).tw.

39. or/33-38

Manual small incision cataract surgery (MSICS) with posterior chamber intraocular lens versus extracapsular cataract extraction 
40. exp extracapsular cataract extraction/

41. (extracapsular adj2 cataract\$).tw.

42. (extra capsular adj2 cataract\$).tw.

43. ECCE.tw.

44. or/40-43

45. (manual adj3 small adj3 incision adj3 cataract\$).tw.

46. (MISICS or SICS).tw.

47. capsulorhexis/

48. (continuous adj3 curvilinear adj3 capsulor?hexis).tw.

49. (continuous adj 3 circular adj 3 capsulor?hexis).tw.

50. (CCC or CCS).tw.

51. (can opener adj5 capsulotom\$).tw.

52. endocapsular.tw.

53. or $/ 45-52$

54.39 and 44 and 53

55.32 and 54

\section{Appendix 4. LILACS search strategy}

cataract\$ and extracapsular or extra capsular or ECCE and manual small incis\$ or MISICS or SICS or capsulorhexis or capsulorrhexis

\section{Appendix 5. Web of Science CPCl-S search strategy}

$\# 16$ \#3 and \#4 and \#15

$\# 15 \# 5$ or $\# 6$ or \#7 or \#8 or \#9 or \#10 or \#11 or \#12 or \#13 or \#14

\#14 TS=endocapsular

\#13 TS=can opener capsulotom*

\#12 TS=(CCC or CCS)

\#11 TS=(continuous circular capsulorrhexis)

\#10 TS=(continuous circular capsulorhexis)

\#9 TS=(continuous curvilinear capsulorrhexis)

\#8 TS=(continuous curvilinear capsulorhexis)

\#7 TS=capsulorhexis

\#6 TS=(MISICS or SICS)

\#5 TS=(manual small incision)

\#4 TS= (extracapsular or extra capsular or ECCE)

\#3 \#1 OR \#2

\#2 TS=(intraocular lens* or intra ocular lens* or $\mathrm{IOL}^{*}$ )

\#1 TS=cataract*

\section{Appendix 6. metaRegister of Controlled Trials search strategy}

cataract and extracapsular 


\section{Appendix 7. ClinicalTrials.gov search strategy}

Cataract AND Extracapsular

\section{Appendix 8. ICTRP search strategy}

cataract and extracapsular

\section{H I S T O R Y}

Protocol first published: Issue 11, 2010

Review first published: Issue 4, 2012

\section{CONTRIBUTIONSOFAUTHORS}

MA and JM were responsible for formulating the review question, writing the protocol for the review, undertaking manual searches, screening search results, screening retrieved papers against the inclusion criteria, writing to authors for additional information, obtaining and screening data on unpublished studies, providing a clinical and policy perspective

MA, JM and JE were responsible for appraising the quality of the papers, extracting data from the trial reports, analysing the data, interpretation of data, providing a methodological perspective and writing the review.

MA and JE were responsible for entering data in to RevMan.

JM was responsible for checking the data that was entered in to RevMan.

\section{DECLARATIONSOF INTEREST}

None known.

\section{SOURCES OF SUPPORT}

\section{Internal sources}

- No sources of support supplied

\section{External sources}

- Sightsavers, UK. 


\section{NOTES}

The updated version of the original published Cochrane review 'Riaz Y, Mehta JS, Wormald R, Evans JR, Foster A, Ravilla T, Snellingen T. Surgical interventions for age-related cataract. Cochrane Database of Systematic Reviews 2006, Issue 4. Art. No.: CD001323. DOI: 10.1002/14651858.CD001323.pub2' has been divided into three smaller reviews each using the same outcome measures as the original review but only comparing two surgical methods within each review. The interventions being compared are ECCE, MSICS and phacoemulsification. Intracapsular extraction (ICCE) is no longer included in the reviews as this technique is no longer used as a primary procedure.

\section{INDEX TERMS}

\section{Medical Subject Headings (MeSH)}

${ }^{*}$ Lenses, Intraocular; Age Factors; Cataract Extraction [adverse effects; ${ }^{*}$ methods]; India; Lens Implantation, Intraocular [ ${ }^{*}$ methods]; Nepal; Posterior Eye Segment; Randomized Controlled Trials as Topic

\section{MeSH check words}

Adult; Aged; Aged, 80 and over; Humans; Middle Aged 